\title{
Dose-dependent effects of luteinizing hormone and follicle stimulating hormone on in vitro maturation, apoptosis, secretion function and expression of follicle stimulating hormone receptor and luteinizing hormone receptor of sheep oocytes
}

\author{
S. Wei ${ }^{1}$, Y. Deng ${ }^{1}$, L. Lai ${ }^{1}$, H. Liang ${ }^{1}$ \& Z. Gong ${ }^{2 \#}$ \\ ${ }^{1}$ College of Life Science and Engineering, Northwest Minzu University, Lanzhou, 730030, P. R. China \\ ${ }^{2}$ Medicine College, Northwest Minzu University, Lanzhou, 730030, P. R. China
}

(Received 4 May 2017; Accepted 31 December 2017; First published online 11 January 2018)

Copyright resides with the authors in terms of the Creative Commons Attribution 4.0 South African License.

See: http://creativecommons.org/licenses/by/4.0/za

Condition of use: The user may copy, distribute, transmit and adapt the work, but must recognize the authors and the South African Journal of Animal Science.

\begin{abstract}
The present study compared the effects of follicle stimulating hormone (FSH) and luteinizing hormone (LH) on in vitro maturation (IVM), apoptosis, and secretion function in sheep oocytes, as well as gene expressions of the receptors (FSHR, LHR, and GnRHR) in cumulus-oocyte complexes (COCs). The COCs were recovered from sheep ovaries and pooled in groups. The COCs were cultured for 24 hours in IVM medium supplemented with various concentrations of $\mathrm{LH}(5-30 \mu \mathrm{g} / \mathrm{mL})$ and FSH $(5-30 \mathrm{IU} / \mathrm{mL})$. They were allocated to LH-1 $(5 \mu \mathrm{g} / \mathrm{mL})$, LH-2 $(10 \mu \mathrm{g} / \mathrm{mL})$, LH-3 $(20 \mu \mathrm{g} / \mathrm{mL})$, and LH-4 $(30 \mu \mathrm{g} / \mathrm{mL})$ groups, and FSH-1 $(5$ $\mathrm{IU} / \mathrm{mL})$, FSH-2 (10 IU/mL), FSH-3 $(20 \mathrm{IU} / \mathrm{mL})$, and FSH-4 $(30 \mathrm{IU} / \mathrm{mL})$ groups. The apoptosis of COCs was assessed by terminal deoxynucleotidyl transferase dUTP nick end labelling (TUNEL). The maturation rates of oocytes improved gradually as LH and FSH concentration increased from 0 to $10 \mu \mathrm{g} / \mathrm{mL}(\mathrm{IU} / \mathrm{mL})$, reaching a peak value of $44.1 \%$ of $\mathrm{LH}-2$ and $48.5 \%$ of $\mathrm{FSH}-2$ group. Oocyte apoptosis rates of $\mathrm{LH}-2$ and $\mathrm{FSH}-2$ groups were the lowest among $\mathrm{LH}$ - and FSH-treated groups, respectively. The germinal vesicle breakdown (GVBD) rate of the FSH-2 group was higher than that of the control group (CG) and FSH-4 groups. The GVBD rate of LH-2 group also increased in comparison with the CG group. FSH concentration of the FSH-2 group was greater than that of CG. Expression levels of FSHR, LHR, and GnRHR mRNAs of FSH-2, LH-3, and LH-3 group, respectively, were higher than CG. Levels of FSHR proteins in FSH-2 and $\mathrm{FSH}-3$ groups were greater than CG. Levels of GnRHR proteins were increased with a maximum increment of FSH-4. The FSH and LH supplemented into the IVM medium could promote the maturation rate, reduce the apoptosis rate of sheep oocytes, and increase FSH concentrations in IVM medium fluid. Additionally, FSH and LH enhanced expression levels of FSHR, LHR, and GnRHR mRNAs of sheep COCs.
\end{abstract}

Keywords: Apoptosis, cumulus-oocyte complexes, germinal vesicle breakdown, protein expression, receptor \#Corresponding author: weisc668@163.com

\section{Introduction}

Currently, gonadotropins are supplemented with in vitro maturation (IVM) medium to stimulate oocyte progression to metaphase II (MII) and development competence of oocytes. Hormones promoted the IVM of sheep oocytes (Lu \& Qi, 2013), but different hormones exert different effects on oocytes in the same animal species (Zou et al., 2012; Yang et al., 2015). Follicle stimulating hormone (FSH), luteinizing hormone (LH) and estradiol (E) have become the most important hormones employed in the IVM of oocytes (Xu et al., 2011; Lu \& Qi, 2013). The addition of $10 \mu \mathrm{g} / \mathrm{mL} \mathrm{FSH}$ and $10 \mu \mathrm{g} / \mathrm{mL}$ LH has been demonstrated to increase the IVM rate of ovine oocytes (Rebecca et al., 2012). The optimal concentration of FSH in IVM medium was $5 \mu \mathrm{g} / \mathrm{mL}$ $\mathrm{FSH}$, which resulted in the greatest cleavage $(79.1 \%)$ and blastocyst rates $(16.1 \%)$ of yak cumulus cells (Xiao et al., 2014). Therefore, adding a suitable dose of FSH to the IVM medium may quicken the maturation rate of oocytes and release of the first polar body (Zhao et al., 2013).

Luteinizing hormone treatment could increase GVBD, the cleavage, blastocyst rates of ovine oocytes compared with the control group after being cultured in vitro for 24 hours. Therefore, LH may play a role in delaying the occurrence of GVBD, and prolonging the maturation duration of cytoplasm (Li et al., 2011). 
Additionally, it promotes the cytoplasm maturation of porcine oocytes (Li et al., 2011). However, currently little information has been reported on LH effects on the IVM of ewe oocytes (Xiao et al., 2014). To date, it is unclear whether supplementation of FSH or LH into IVM medium affects maturation and apoptosis of oocytes in Lanzhou fat-tailed sheep (de Frutos et al., 2013; Wei et al., 2016), or which dose of FSH and LH in IVM medium is the optimum of IVM of oocytes in this breed of sheep.

For $\mathrm{FSH}$ and $\mathrm{LH}$ to act, $\mathrm{FSH}$ receptor (FSHR) and $\mathrm{LH}$ receptor (LHR) must be expressed by the cumulus cells (Calder et al., 2003; Xiao et al., 2014). Previous studies of mice and rats showed that the cumulus cells had high numbers of FSHR, but little or no LHR (Peng et al., 1991). Wei et al. (2013) reported that FSHR, LHR, and gonadotropin-releasing hormone receptors (GnRHR) are expressed in ovaries of sheep. Another report about bovines indicated that FSHR and its mRNA were expressed in cumulus cells and granulosa cells, but not the mRNA of the LHR (Van Tol et al., 1996). Genes of FSHR, LHR, and GnRHR exist in the ovaries and follicle of sheep. However, little information has been recorded as to whether FSH and LH affect expression levels of FSHR, LHR, and GnRHR mRNAs and proteins in COCs of Lanzhou fat-tailed sheep (Nor-Azlina et al., 2014; Wei et al., 2016).

Lanzhou fat-tailed sheep are unique sheep breeds in Lanzhou areas (latitude N $35^{\circ} 34$ to N $38^{\circ} 10$, longitude $\mathrm{E} 102^{\circ} 30$ to $\mathrm{E} 104^{\circ} 37$ ) of China. The breed is characterized by a big tail, fast development, fleshiness, full fat, and delicious meat. However, competence in embryonic development is poor. Their lambing percentage is only about $117 \%$ (Zhang, 2010). Therefore, improving their reproductive performance to raise the quantity of population has become urgent. So far, there has been little information about oocyte IVM in this species. In this investigation, the effects of various concentrations of LH and FSH were studied on IVM and apoptosis of Lanzhou fat-tailed sheep oocyte, and their impacts on the expression levels of FSHR, LHR, and GnRHR mRNAs and proteins were compared, aiming to improve the breeding process.

The current investigation aimed to study the effects of adding various concentrations of FSH or LH into the IVM medium on IVM of sheep oocytes, and to determine the optimal concentration of FSH or LH supplemented into the IVM medium. Additionally, the study aimed to explore their impact on the expression levels of FSHR, LHR and GnRHR mRNAs and proteins in COCs after 24 hours IVM, with the aim of facilitating the fecundity and treating ovarian diseases (such as hypoplasia of ovaries, ovarian cyst, and persistent corpus luteum) of Lanzhou fat-tailed sheep.

\section{Materials and Methods}

Basal culture medium (bMM) consisted of $9.5 \mathrm{~g}$ medium 199 powders (Sigma, St. Louis, MO, USA), $26.0 \mathrm{mM} \mathrm{NaHCO}, 0.23 \mathrm{mM}$ sodium pyruvate, $20.0 \mathrm{mM}$ 4-(2-hydroxyethyl)-1- piperazineethanesulfonic acid (HEPES), $50 \mu \mathrm{g} / \mathrm{L}$ ampicillin sodium, $50 \mu \mathrm{g} / \mathrm{L}$ streptomycin sulfate, and ultrapure water to a final volume of $1000 \mathrm{~mL}$. This medium was filtered through a $0.22-\mu \mathrm{m}$ membrane and stored at $4{ }^{\circ} \mathrm{C}$. The maturation medium comprised bMM supplemented with $0.68 \mathrm{mM}$ L-glutamine, $2.1 \mathrm{~g} \mathrm{NaHCO}_{3}, 10 \%$ foetal calf serum ( $\mathrm{v} / \mathrm{v}$; HyClone, Logan, UT, USA), and 5\% foetal bovine serum (FBS) (Minhai Company, Lanzhou, China).

Ovaries were collected between September and November 2014 from 530 pubertal ewes (6-7 months old) immediately after their slaughter at the local shambles. They were transported to the laboratory in Dulbecco's phosphate-buffered saline (DPBS) (Sigma Co. Ltd, Beijing, China), and placed at $30-35^{\circ} \mathrm{C}$ within three hours of collection. Use of these animals was approved by the Institutional Animal Ethics Committee of Northwest University for Nationalities, and all experiments were conducted according to the conventions of the Committee for the Purpose of Control and Supervision of Experiments on Animals in China.

The redundant tissues and fat on ovary surfaces were removed using sterile scissors. The ovaries were placed in a petri dish, to which $2 \mathrm{~mL}$ pre-equilibrated extraction fluid (phosphate-buffered saline (PBS) containing $3 \mathrm{mg} / \mathrm{mL}$ bovine serum albumin, incubated at $38^{\circ} \mathrm{C}$ overnight) was added, while they were gently held in place using sterile ophthalmic tweezers. Follicles on the ovarian surface were then scratched with a scalpel blade. The COCs were recovered by gently cutting follicles with a scalpel on a petri dish. The COCs were collected from each animal and pooled in groups. They were washed twice in Medium 199 (Sigma) supplemented with $0.68 \mathrm{mM}$ L-glutamine (Sigma), $1 \mathrm{mM}$ pyruvate, $20 \mathrm{mM}$ HEPES (Sigma), $100 \mathrm{U} / \mathrm{mL}$ penicillin (Sigma), $100 \mu \mathrm{g} / \mathrm{mL}$ streptomycin (Sigma), and 10\% FBS (Invitrogen, Carlsbad, CA, USA). Oocytes with intact cumulus cells and a homogeneous cytoplasm were selected and classified into four grades (A, B, C, and D) according to their cumulus cell layers (Nandi et al., 2002; Tripathi et al., 2016). Only COCs with at least three complete cumulus cell layers were considered suitable for IVM. The COCs from all animals were collected in one instrument tray. Samples were collected three times. Four to five COCs were harvested from each ovary. Each experiment was replicated in triplicate. A total of 1086 COCs were used for subsequent experiments.

A micro-well culture system was utilized in this experiment. Collected COCs were rinsed three times with extraction fluid, and pre-equilibrated for three hours before IVM culture. At least $30 \mathrm{COCs}$ were randomly taken from the instrument tray and placed in one culture well (Nunc Inc., Naperville IL, USA) containing 600 
$\mu \mathrm{L}$ maturation medium with various concentrations of $\mathrm{FSH}(5,10,20$, and $30 \mathrm{IU} / \mathrm{mL})$ or $\mathrm{LH}(5,10,20$, and 30 $\mu \mathrm{g} / \mathrm{mL}$ ) (Ningbo Sansheng Hormone Factory, Ningbo, China), covered with $300 \mu \mathrm{L}$ mineral oil. COCs were then left to complete their maturation at $38.5^{\circ} \mathrm{C}$ in an atmosphere of $5.0 \%$ carbon dioxide in humidified air for 24 hours.

FSH-treated COCs were allocated to FSH-1 (5 IU/mL), FSH-2 (10 IU/mL), FSH-3 $(20 \mathrm{IU} / \mathrm{mL})$, and FSH-4 $(30 \mathrm{IU} / \mathrm{mL})$ groups. Similarly, LH-treated COCs were allocated to LH-1 $(5 \mu \mathrm{g} / \mathrm{mL}), \mathrm{LH}-2(10 \mu \mathrm{g} / \mathrm{mL})$, LH-3 $(20 \mu \mathrm{g} / \mathrm{mL})$, and LH-4 groups $(30 \mu \mathrm{g} / \mathrm{mL})$. COCs without FSH or LH treatment were allocated to the blank control group (CG).

After IVM, oocytes were denuded by $0.3 \%$ hyaluronidase digestion following three PBS rinses. Mature denuded oocytes were then fixed and subjected to Giemsa staining to determine their progression to MII. The harvested oocytes were observed under a microscope, and those displaying an intact first polar body were deemed mature.

To evaluate nucleus maturation, oocytes were recovered under a stereomicroscope and transferred onto glass slides in a small drop of fluid. The slides were immersed in a $3: 1$ fixative solution of ethanol/acetic acid for a minimum of 24 hours. Nucleus morphology was evaluated by staining with $1 \%$ lacmoid, and specimens were examined under a phase contrast microscope. Oocytes were classified as: immature (germinal vesicle (GV) and GVBD stage), intermediate, and matured (MII). GV and GVBD rates of oocytes were calculated.

All COCs, having undergone IVM, were mounted and observed under a microscope to identify apoptosis cells according to morphological criteria (Yang \& Rajamahendran, 2000). To estimate rates of apoptosis, COCs in each group were analysed with a TUNEL (terminal deoxynucleotidyl transferase dUTP nick end labelling) kit, following the manufacturer's instructions (Roche Molecular Biochemicals, Mannheim, Germany). Briefly, COCs were fixed in $4 \%$ PBS-buffered paraformaldehyde for 20 min at $23-25{ }^{\circ} \mathrm{C}$, before being washed three times with $0.1 \%$ polyvinyl alcohol in PBS, and permeabilized with $0.5 \%$ Triton $\mathrm{X}-100$ in PBS for $10 \mathrm{~min}$. Positive-control COCs were treated with $50 \mathrm{U} / \mathrm{mL}$ RNAse-free DNAse in cacodylate buffer for 1 hour at $37.5^{\circ} \mathrm{C}$. COCs were placed in $30 \mathrm{~mL}$ drops of TUNEL solution and incubated in the dark for 1 hour at $37.5^{\circ} \mathrm{C}$. For the negative control group, the TUNEL reagent was omitted. Apoptosis was reported as the number of labelled cells expressed as a percentage of the total cell number.

To investigate the effects of the addition of FSH to the IVM medium on concentrations of $\mathrm{FSH}, \mathrm{LH}$ and progesterone $(\mathrm{P})$ after IVM of COCs, these concentrations were quantified using a special FSH, LH and progesterone kit for sheep (ELISA), according to the manufacturer's instructions (Cusabio Biotech Co., Ltd. Wuhan, P.R. China). IVM medium was collected and pooled after COCs were cultured in vitro for 24 hours, and then centrifuged at $3000 \times \mathrm{g}$ for $15 \mathrm{~min}$. The supernatant was separated and used for the subsequent assay of hormones.

The minimum limits of detection were $0.10 \mu \mathrm{g} / \mathrm{L}$ for $\mathrm{FSH}, 0.25 \mathrm{ng} / \mathrm{ml}$ for $\mathrm{LH}$, and $0.03 \mathrm{ng} / \mathrm{ml}$ for P. The intra- and inter-assay coefficient of variations were lower than $8 \%$. The sensitivity was $0.01 \mu \mathrm{g} / \mathrm{L}$ for FSH, 0.02 $\mathrm{ng} / \mathrm{ml}$ for $\mathrm{LH}$, and $0.002 \mathrm{ng} / \mathrm{ml}$ for P. The correlation coefficient of the standard curve was $0.9981,09975$ and 0.9995 for FSH, LH, and P, respectively. The detailed operation steps were reported in the authors' initial research (Wei et al., 2012). Each assay was repeated in triplicate.

To assess the effect of the addition of FSH in IVM media on FSHR, LHR and GnRHR mRNAs expression in COCs after IVM, primers specific to FSHR (GenBank accession number: NM-001009289.1), LHR (GenBank accession number: L36329.1) and GnRHR (GenBank accession number: NM-001009397.1) were designed with Beacon Designer 7.0 software (Premier Biosoft International, Palo Alto, CA, USA) according to manufacturers' guidelines. Primer-BLAST on NCBI (Table 1). Ovine GAPDH (GenBank accession No. HM043737.1) was chosen as an internal reference for normalization of target gene expression. Melting curve analysis was used to test various primer concentrations (100,200,300, and $500 \mathrm{nM}$ ) and check for the primer dimer formation. Only those primer concentrations that resulted in dimer-free reactions were used in the final analysis. Primers and probes were synthesized by Beijing AoKeDingSheng Biotechnology Co. Ltd. (Beijing, China).

A total RNA of $30 \mathrm{COCs}$ was extracted from cumulus cells after IVM (during which cells were exposed to IVM medium containing various FSH and LH concentrations) using TRIzol reagent (Invitrogen, Beiiing, China) according to the manufacturer's instructions, before being reverse transcribed with PrimeScript ${ }^{\mathrm{TM}} \mathrm{RT}$ reagent kit (TaKaRa Co., Dalian, China) according to the manufacturer's instructions (Wei et al., 2013; Wei et al., 2016). The amount of $100 \mu \mathrm{g}$ RNA was used for the experiment. The extraction was replicated three times. 
Table 1 Primers used to amplify genes of follicle stimulating hormone receptor, luteinizing hormone receptor and gonadotropin-releasing hormone receptor of sheep

\begin{tabular}{llccc}
\hline Target & Primer & Sequence $\left(\mathbf{5}^{\prime}-\mathbf{3}^{\prime} \mathbf{)}\right.$ & $\mathbf{T}_{\mathbf{m}}\left({ }^{\circ} \mathbf{C}\right)$ & Product $(\mathbf{b p})$ \\
\hline \multirow{2}{*}{ FSHR } & Forward & TCTTTGCTTTTGCAGTTGCC & 59.1 & 126 \\
& Reverse & GCACAAGGAGGGACATAACATAG & 58.4 & \\
\multirow{2}{*}{ LHR } & Forward & CCTGAAGAAGATGCACGATGACGCC & 60.2 & 189 \\
& Reverse & ACCCATTCCCTGTCTGCCAGTCT & 59.3 & \\
\multirow{2}{*}{ GnRHR } & Forward & TTCGGAGTATTCAGCAACCAAC & 59.2 & \multirow{2}{*}{161} \\
& Reverse & CAGGAATGTTCTATCCCCCAGT & 59.7 & \multirow{2}{*}{152} \\
\multirow{2}{*}{ GAPDH } & Forward & CTTCAACAGCGACACTCACTCT & 57.1 & \\
& Reverse & CCACCACCCTGTTGCTGTA & 57.0
\end{tabular}

$\mathrm{T}_{\mathrm{m}}$ : melting temperature, FSHR: follicle stimulating hormone receptor, LHR: luteinizing hormone receptor, GnRHR: gonadotropin-releasing hormone receptor, GAPDH: glyceraldehyde 3-phosphate dehydrogenase

The expression of FSHR, LHR, and GnRHR mRNA was determined using qRT-PCR (Wei et al., 2013; Wei et al., 2014). Briefly, on 96-well plates, $25-\mu \mathrm{L}$ reactions were carried out, each comprising $4 \mu \mathrm{L}$ complementary DNA template (diluted $1: 50$ ), $1 \mu \mathrm{L}$ each primer pair at $10 \mu \mathrm{M}, 0.25 \mu \mathrm{L} 10 \mu \mathrm{M}$ TaqMan probe, and $12.5 \mu \mathrm{L}$ 10X TaqMan Universal PCR Master Mix containing DNA polymerase, buffer, deoxynucleotides, and SYBR Green II (Promega corporation, Beijing, China). Plates were sealed with optical adhesive film (Promega). After an initial denaturation step of $15 \mathrm{~min}$ at $95^{\circ} \mathrm{C}, 44$ cycles of amplification were performed as follows: denaturation for $30 \mathrm{~s}$ at $95^{\circ} \mathrm{C}$, annealing for $20 \mathrm{~s}$ at $60^{\circ} \mathrm{C}$, and extension for $20 \mathrm{~s}$ at $72{ }^{\circ} \mathrm{C}$. GAPDH was used as an endogenous control, and the $2^{-\Delta \Delta C t}$ method was employed to calculate relative mRNA expression (Wei et al., 2013; Wei et al., 2014). Samples were analysed in triplicate with 30 COCs for each replicate.

To evaluate FSHR, LHR, and GnRHR expression levels in sheep COCs after IVM, western blotting was conducted as described previously (Wei et al., 2013). Briefly, COCs were lysed in lysis buffer, and the resulting proteins were subjected to $10 \%$ sodium dodecyl sulfate-polyacrylamide gel electrophoresis, before being transferred to polyvinylidene fluoride membranes. These membranes were then blocked for two hours in a $5 \%$ non-fat milk solution containing $10 \mathrm{mM}$ Tris $(\mathrm{pH} 7.5), 100 \mathrm{mM} \mathrm{NaCl}$, and $0.1 \%$ Tween $20(\mathrm{w} / \mathrm{v})$. Membranes were incubated with rabbit anti-sheep GnRHR, FSHR, LHR (Sigma, diluted 1:200), and rabbit anti-sheep $\beta$-actin (1:1000) polyclonal antibodies at $4{ }^{\circ} \mathrm{C}$ overnight, before being exposed to the appropriate secondary antibody (1:2000) for 1 hour. Mouse anti- $\beta$-actin monoclonal antibody $(1: 10000)$ was used as a sample loading control. Blots were developed using a chemiluminescent reagent (SuperSignal West Pico, Thermo Scientific, Rockford, IL, USA). Integrated optical densities of bands in the scanned images were measured with Quantity One software (Bio-Rad, Hercules, CA, USA). Relative protein expression was calculated as the ratio of the grey value of the target band (FSHR, LHR, or GnRHR) to that of the $\beta$-actin band. Samples were executed in triplicate. The negative control was not incubated with the primary antibodies.

Data on maturation rates, apoptosis rates, GVBD rates, GV rates and hormone contents were reported as means \pm standard error of means. Statistical analysis was performed with SPSS version 18.0 (SPSS Inc., Chicago, IL, USA). After square root transformation of the data, all variables complied with the assumptions of one-way analysis of variance (ANOVA). When significant differences were identified, supplementary Tukey's post-hoc tests were performed to investigate pairwise differences. $P$-values of $<0.05$ were considered significant.

\section{Results}

The maturation rate of sheep oocytes improved gradually as FSH or LH concentration increased from 0 (CG) to $10 \mathrm{IU} / \mathrm{mL}$ (or $10 \mu \mathrm{g} / \mathrm{mL}$ ), reaching a peak value of $\mathrm{FSH}-2$ (or $\mathrm{LH}-2$ ) group (Table 2). The current results revealed that $10 \mathrm{IU} / \mathrm{mL}$ and $10 \mu \mathrm{g} / \mathrm{mL}$ were the optimal concentrations of $\mathrm{FSH}$ and LH for sheep oocyte IVM, respectively.

However, oocyte maturation rates of the LH treatment group were lower than that of FSH treatment group. The results indicated that the supplementation of FSH into the IVM medium had more efficacy than LH 
in promoting IVM of sheep oocytes.

Table 2 In vitro maturation rate and apoptosis rate of sheep oocytes after supplementation of different doses of follicle stimulating hormone and luteinizing hormone into the in vitro maturation medium

\begin{tabular}{lcccccc}
\hline Group & Treatment & Cultured oocytes & Matured oocytes & Maturation rate \% & $\begin{array}{c}\text { Apoptotic } \\
\text { oocytes }\end{array}$ & $\begin{array}{c}\text { Apoptosis } \\
\text { rate } \%\end{array}$ \\
\hline CG & 0 & 124 & 24 & $38.7 \pm 4.2$ & 18 & $29.0 \pm 2.6$ \\
\hline FSH-1 & 5 & 127 & 55 & $43.5^{\mathrm{a}} \pm 4.5$ & 31 & $24.6^{\mathrm{b}} \pm 2.2$ \\
$\mathrm{FSH}-2$ & 10 & 125 & 61 & $48.5^{* \mathrm{~b}} \pm 4.6$ & 26 & $20.6^{\star *} \pm 1.8$ \\
$\mathrm{FSH}-3$ & 20 & 134 & 62 & $46.3^{* \mathrm{~b}} \pm 4.5$ & 30 & $22.4^{\mathrm{a}} \pm 2.1$ \\
$\mathrm{FSH}-4$ & 30 & 130 & 58 & $44.6^{\mathrm{a}} \pm 4.3$ & 32 & $24.5^{\mathrm{b}} \pm 2.6$ \\
\hline LH-1 & 5 & 110 & 42 & $38.2^{\mathrm{b}} \pm 3.6$ & 26 & $23.6^{\mathrm{a}} \pm 2.4$ \\
LH-2 & 10 & 118 & 52 & $44.1^{* \mathrm{c}} \pm 3.9$ & 24 & $20.3^{\star \star} \pm 2.1$ \\
LH-3 & 20 & 110 & 42 & $38.2^{\mathrm{b}} \pm 3.7$ & 24 & $21.8^{\mathrm{a}} \pm 2.1$ \\
LH-4 & 30 & 108 & 36 & $33.3^{\mathrm{a}} \pm 3.5$ & 28 & $25.9^{\mathrm{b}} \pm 2.7$ \\
\hline
\end{tabular}

CG was a blank control group, $\mathrm{FSH}$ : follicle stimulating hormone, $\mathrm{LH}$ : luteinizing hormone

${ }^{*} P<0.05$ and ${ }^{* *} P<0.01$ compared with group CG (blank control)

The different superscripts in the same column means that there was a significant difference between experimental groups, of which adjacent superscripts (such as ab, bc) indicate the difference was significant $(P<0.05)$, while interval superscripts (such as ac) indicate that the difference was highly significant $(P<0.01)$

Based on the evaluation of nucleus morphology by staining with $1 \%$ lacmoid and examination under a phase contrast microscope, results in Table 3 shows that GVBD rate of FSH-2 and LH-2 was higher than that of $\mathrm{CG}$ and $\mathrm{FSH}-4$ and $\mathrm{LH}-4(P<0.05)$. The GV rates in the $\mathrm{FSH}$-treated and $\mathrm{LH}$-treated groups were decreased in comparison with CG. The smallest value of GV rates was determined in the FSH-2 group compared with CG $(P<0.01)$. The lowest GV rate was found in $\mathrm{FSH}-2$ and $\mathrm{LH}-2$ group. The results demonstrated that addition of $10 \mathrm{IU} / \mathrm{mL} \mathrm{FSH}$ or $10 \mu \mathrm{g} / \mathrm{mL}$ LH to the IVM medium could increase the GVBD rate and the decrease GV rate of oocytes. These hormones could promote the IVM of oocytes. The optimal concentration of $\mathrm{FSH}$ and $\mathrm{LH}$ was $10 \mathrm{IU} / \mathrm{mL}$ and $10 \mu \mathrm{g} / \mathrm{mL}$

The incidence of apoptosis in COCs is presented in Table 2 and Figure 1 on the basis of TUNEL assays. Apoptosis level was lowest in FSH-2 compared with the control group (CG) (29.0\% vs $20.6 \%)$. In LH-treated groups, apoptosis rates were lower than CG (LH-1). Apoptosis was lowest in group LH-2 compared with CG. However, oocyte maturation rates of LH treatment group were lower than those of FSH group. The results indicated that FSH had greater efficacy than LH in promoting the maturation of sheep oocytes.

The FSH, LH, and $\mathrm{P}$ concentration in IVM medium supplemented doses of FSH were detected using ELISA kit (Table 4). The FSH concentrations in the IVM medium of FSH-treated groups increased compared with CG (basal line), with a maximum increment of the FSH-2 group. The FSH concentration of the FSH-2 group was higher than that of the $\mathrm{FSH}-4$ group $(P<0.05)$. However, $\mathrm{LH}$ and $\mathrm{P}$ concentrations decreased gradually. The largest reduction in both $\mathrm{LH}$ and $\mathrm{P}$ concentrations was determined in $\mathrm{FSH}-4$. The results indicated the addition of $10 \mathrm{IU} / \mathrm{mL}$ FSH to the IVM medium could promote FSH concentration. The addition of $30 \mathrm{IU} / \mathrm{mL}$ FSH to IVM medium could significantly decline LH and P concentrations.

The results of real-time RT-PCR (qRT-PCR) of FSHR, LHR and GnRHR mRNAs are shown in Figure 2. FSHR, LHR and GnRHR mRNAs were detected in sheep COCs after in vitro maturation. In FSH-treated groups, expression levels of FSHR, LHR and GnRHR mRNA were enhanced after FSH was added to IVM medium. The greatest increments of FSHR and LHR mRNA were detected in FSH-2 $(P<0.01$ or $P<0.05)$, respectively, compared with CG. The greatest increments of FSHR, LHR or GnRHR mRNA were detected in FSH-2, LH-3 and LH-3 groups, respectively, compared with CG (basal line). The FSHR mRNA level of FSH-2 was higher than that of LH-1. The LHR mRNA level of the LH-1 group was less than that of the LH-2, LH-3 and LH-4 groups. 
Table 3 Germinal vesicle and germinal vesicle break down rate of oocytes after in vitro maturation (mean \pm SEM)

\begin{tabular}{lccc}
\hline Group & oocytes & GVBD rate $\%$ & GV rate $\%$ \\
\hline CG & 124 & $40.6 \pm 3.7$ & $20.0 \pm 2.8$ \\
FSH-1 & 127 & $41.9^{\mathrm{a}} \pm 4.8$ & $15.3^{* \mathrm{~b}} \pm 1.9$ \\
FSH-2 & $42.5^{* \mathrm{~b}} \pm 4.3$ & $9.5^{* \mathrm{a}} \pm 1.1$ \\
FSH-3 & 125 & $40.0^{\mathrm{a}} \pm 4.5$ & $11.7^{* \mathrm{a}} \pm 2.0$ \\
FSH-4 & 134 & $39.6^{\mathrm{a}} \pm 3.2$ & $12.9^{* \mathrm{a}} \pm 2.2$ \\
LH-1 & 130 & $41.2^{\mathrm{a}} \pm 3.7$ & $18.0^{\mathrm{b}} \pm 2.1$ \\
LH-2 & 110 & $43.0^{* \mathrm{~b}} \pm 4.3$ & $12.1^{* \mathrm{a}} \pm 1.9$ \\
LH-3 & 118 & $40.4^{\mathrm{a}} \pm 3.7$ & $17.6^{* \mathrm{~b}} \pm 2.8$ \\
LH-4 & 110 & $38.1^{\mathrm{a}} \pm 3.2$ & $16.9^{\mathrm{b}} \pm 3.3$
\end{tabular}

CG was a blank control group, GV: germinal vesicle, GVBD: germinal vesicle break down, FSH: follicle stimulating hormone, LH: luteinizing hormone

${ }^{*} P<0.05$ when compared with $C G$ (basal line); ${ }^{* *} P<0.01$ when compared to CG (basal line)

The different superscripts in the same column mean that there was a significant difference between experimental groups, of which adjacent superscripts (such as ab, bc) indicate the difference was significant $(P<0.05)$, while interval superscripts (such as ac) indicate that the difference was highly significant $(P<0.01)$
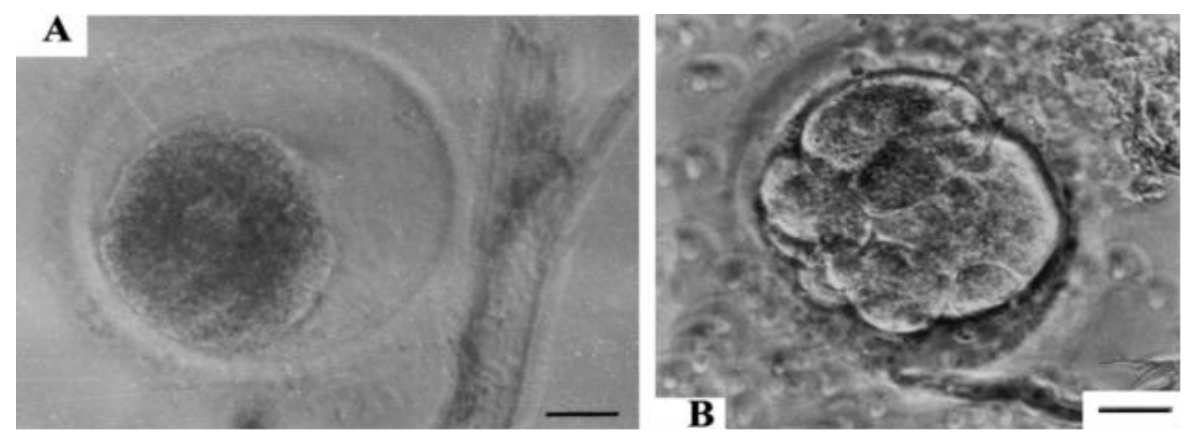

(Scale bar represents $=25 \mu \mathrm{m}$ )

Apoptosis morphological features were evident in cumulus masses of COCs at 26h of IVM (Figure 1). It showed that the shrinkage or occurrence of cytoplasmic condensation, membrane blebbing, pyknotic appearance, multiple nuclear fragments and apoptosis body formation.

Figure 1 Cytoplasmic condensation (A) and fragmentation (B) in cumulus-oocyte complexes (COCs) at 26h of in vitro maturation

In LH-treated groups, the expression levels of FSHR, LHR and GnRHR mRNAs of four LH-treated groups were increased compared with CG, with a maximum increment in LH-4, LH-3, and LH-3 group $(P$ $<0.05, P<0.01$ or $P<0.05$ ), respectively. LHR mRNA level of $\mathrm{LH}-1$ group were less than that of LH-2, LH-3, and LH-4 groups $(P<0.05)$.

Additionally, FSHR mRNA level of FSH-2 was higher than that of $\mathrm{LH}-1, \mathrm{LH}-2$, and $\mathrm{LH}-3$ groups $(P$ $<0.05)$. Contrarily, LHR mRNA levels of four FSH groups were lower than those of LH-2, LH-3, and LH-4 groups $(P<0.05)$. The findings in this study demonstrated that supplementation of FSH and LH to the IVM medium could increase the expression of FSHR, LHR, and GnRHR mRNAs.

Expression of FSHR, LHR, and GnRHR proteins in sheep COCs was detected by western blotting. As shown in Figure 3, the levels of three receptor proteins were increased gradually after FSH and LH were supplemented into the IVM medium. In FSH-treated groups, levels of FSHR proteins in FSH-2 and FSH-3 groups were significantly increased compared with CG $(P<0.05)$. There were no obvious differences in LHR protein expression among FSH-treated groups. 
Table 4 Follicle stimulating hormone, luteinizing hormone and progesterone concentration in medium after in vitro maturation (Mean \pm SEM)

\begin{tabular}{llll}
\hline Group & FSH $(\boldsymbol{\mu g} / \mathbf{L})$ & LH $(\mathbf{n g} / \mathbf{L})$ & $\mathbf{P}(\mathbf{n g} / \mathbf{L})$ \\
\hline CG & $9.00 \pm 0.82$ & $890.9 \pm 91.0$ & $319.9 \pm 47.0$ \\
FSH-1 & $9.91^{\mathrm{a}} \pm 1.05$ & $688.7^{\mathrm{b}} \pm 33.9$ & $304.8^{\mathrm{b}} \pm 33.9$ \\
$\mathrm{FSH}-2$ & $10.52^{* \mathrm{~b}} \pm 0.97$ & $594.6^{\mathrm{a}} \pm 57.1$ & $288.7^{\mathrm{a}} \pm 31.6$ \\
$\mathrm{FSH}-3$ & $10.10^{\mathrm{a}} \pm 1.49$ & $539.8^{* \mathrm{a}} \pm 37.9$ & $285.7^{\mathrm{a}} \pm 17.8$ \\
FSH-4 & $9.32^{\mathrm{a}} \pm 0.76$ & $504.4^{* \mathrm{a}} \pm 44.8$ & $246.4^{* \mathrm{a}} \pm 16.9$ \\
\hline
\end{tabular}

${ }^{-}$$P<0.05$ when compared with CG (basal line)

FSH-1, FSH-2, FSH-3 and FSH-4 groups represent the follicle stimulating hormone supplementation into the maturation medium at concentrations of $5,10,20$ and $30 \mathrm{IU} / \mathrm{mL}$, respectively

The different superscripts in the same column mean that there was a significant difference between experimental groups $(P<0.05)$

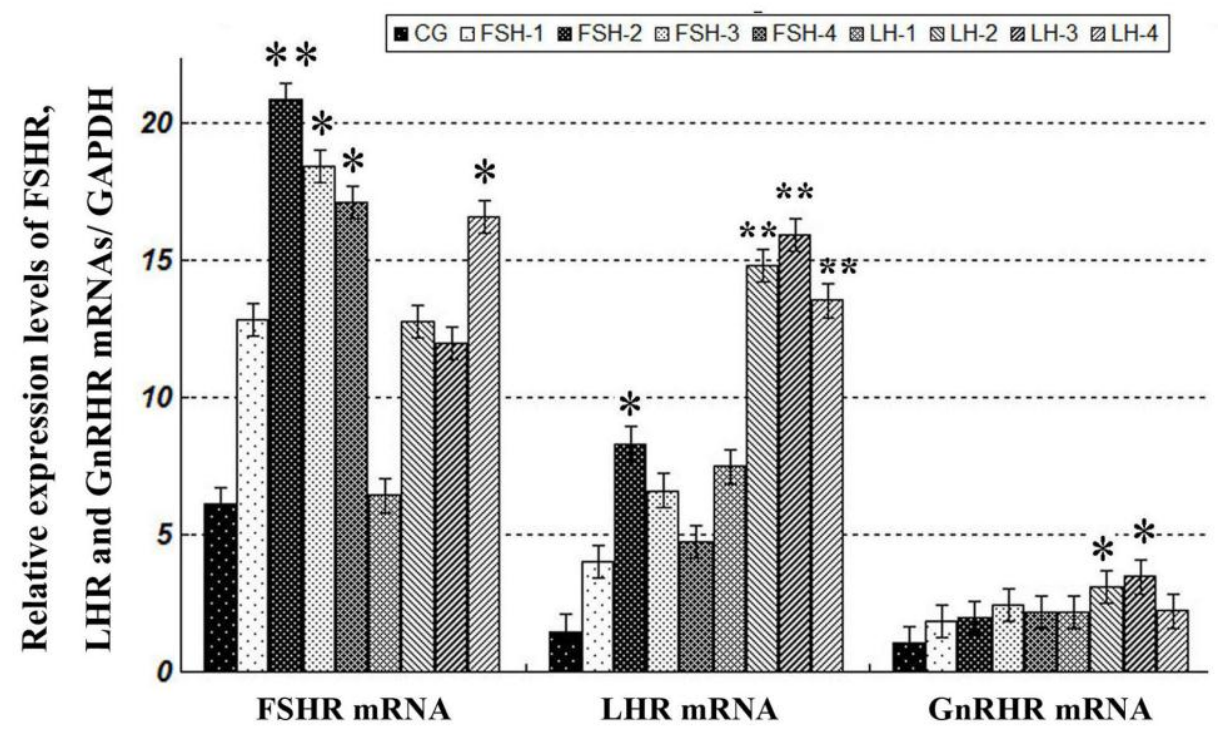

${ }^{*} P<0.05$ and ${ }^{* *} P<0.01$ compared to the control group (eCG-1).

Figure 2 Expression of follicle stimulating hormone receptor, luteinizing hormone receptor and gonadotropin-releasing hormone receptor mRNAs

In LH-treated groups, the expression level of LHR protein of LH-2 was higher than that in CG $(P<0.05)$. Statistical analysis indicated no significant differences in FSHR protein expression among $\mathrm{LH}$-treated groups and $C G(P>0.05)$.

Expression levels of GnRHR proteins were increased gradually in $\mathrm{FSH}$-treated and $\mathrm{LH}$-treated groups with a maximum increment of $\mathrm{FSH}-4$ and $\mathrm{LH}-4(P<0.05)$.

The findings in this research demonstrated that the addition of FSH to the IVM medium could strengthen expressions of FSHR proteins. Supplement of $10 \mu \mathrm{g} / \mathrm{mL}$ LH slightly enhanced expressions of LHR protein expressions of LHR. A higher dose of FSH $(30 \mathrm{IU} / \mathrm{mL})$ and of $\mathrm{LH}(30 \mu \mathrm{g} / \mathrm{mL})$ promoted expressions of GnRHR proteins. 


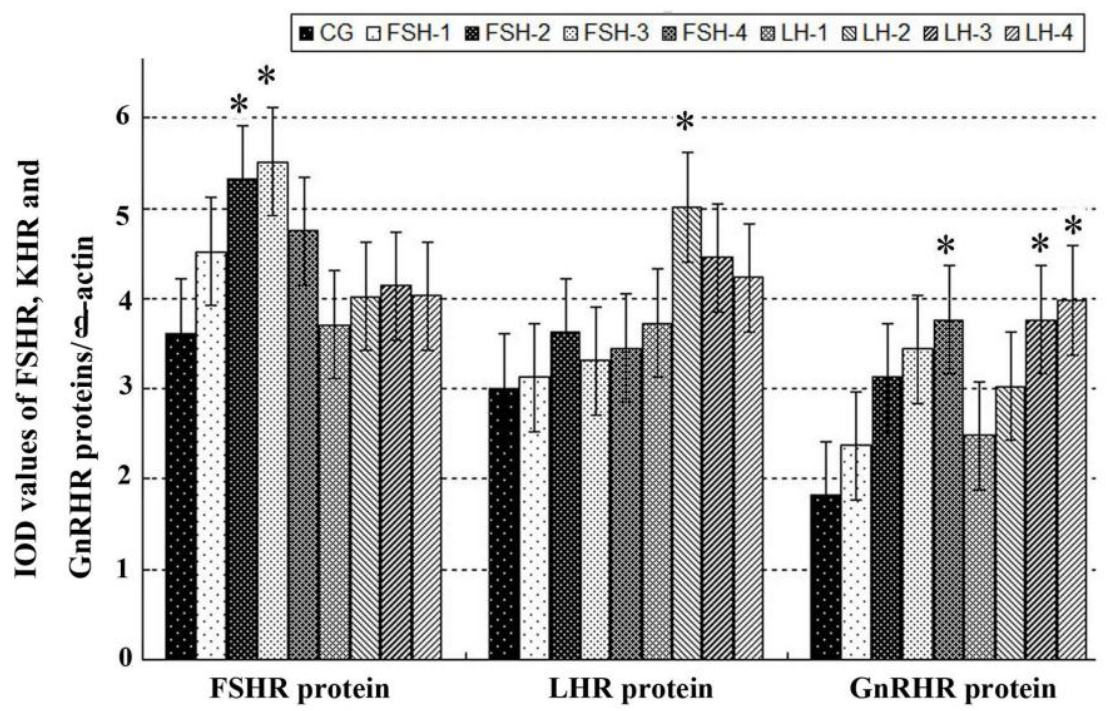

${ }^{*} P<0.05$ when compared to control group (CG)

${ }^{*} P<0.01$ when compared to control group (CG)

IOD: integrated optical density

Figure 3 Expression of follicle stimulating hormone receptor, luteinizing hormone receptor and gonadotropin-releasing hormone receptor proteins

\section{Discussions}

The extrusion of the first polar body is the main sign of oocyte IVM and nucleus maturation. A previous study reported that the maturation of the cytoplasm and nucleus in cumulus cells was synchronous in vivo. However, the maturity of the nucleus is achieved prior to that of the cytoplasm in vitro. FSH and LH can be used to promote the IVM of oocyte (Lu \& Qi, 2013; Yang et al., 2015). To date, it is undetermined which dose of FSH or LH in IVM medium is the optimum IVM of Lanzhou fat-tailed sheep oocytes, although the initial studies indicated that FSH yielded a high degree of cumulus expansion and enhanced progression of oocytes to the MII stage in the IVM of sheep oocytes (de Frutos et al., 2013).

The supplementation of IVM medium with $1.5 \mu \mathrm{g} / \mathrm{L} \mathrm{rbFSH}$ yielded a high degree of cumulus expansion of sheep oocytes. Likewise, the addition of rbFSH enhanced the progression of oocytes to the MII stage. These results indicate that rbFSH is necessary and sufficient to induce sheep oocyte maturation in a high proportion of oocytes (de Frutos et al., 2013). However, the optimal FSH concentration for IVM of sheep oocytes is undetermined. In the present study, the maturation rates of oocytes were improved gradually as the FSH doses in the IVM increased from 0 to $10 \mu \mathrm{g} / \mathrm{mL}$ (FSH-2 group). These findings agreed with earlier reports (Yang et al., 2015; de Frutos et al., 2013), which stated that the addition of various doses of FSH (10, 50, 100, 200 , and $300 \mu \mathrm{g} / \mathrm{mL}$ ) (Yang et al., 2015), and $1.5 \mu \mathrm{g} / \mathrm{mL}$ recombinant bovine FSH or LH (de Frutos et al., 2013) could enhance the IVM of sheep oocytes. But the molecular mechanism needs to be studied thoroughly.

Early documents reported that the addition of $5 \mu \mathrm{g} / \mathrm{mL}$ and $10 \mu \mathrm{g} / \mathrm{mL}$ LH to IVM medium could raise the maturation rates of oocytes (Li et al., 2011; Zou \& Huo, 2012; de Frutos et al., 2013). But, $20 \mu \mathrm{g} / \mathrm{mL} \mathrm{LH}$ inhibited oocyte maturation. In this present study, the maturation rates of $\mathrm{LH}$-treated oocytes were gradually increased as LH concentrations increased from 0 (control group) to $10 \mu \mathrm{g} / \mathrm{mL}$ (group LH-2). The optimal LH concentration for IVM of sheep oocyte was $10 \mu \mathrm{g} / \mathrm{mL}$. However, oocyte maturation rates of $\mathrm{LH}$ treatment groups were lower than those of FSH treatment groups. FSH had more efficacy than LH for promoting IVM of sheep oocytes.

Apoptosis of oocytes could be a good marker for oocyte quality and development competency. In the ovary, oocytes with early signs of atresia have excellent developmental potential (Nor-Azlina et al., 2014). Previous studies have indicated that oocyte apoptosis affected embryo quality, the presence of molecules that regulate the apoptosis mechanism in the maternal mRNA stored in the oocytes (Metcalfe et al., 2004). A later study indicated significant changes in transcript abundance in oocytes and their surrounding cumulus cells and apoptotic index accompanied by the differences in oocyte developmental capacity after IVM (Arias-Álvarez et al., 2016). In the presence of FSH, IVM medium could promote maturation and reduce the apoptosis rate of sheep oocytes. The authors found that the apoptosis rates of FSH-treated groups were 
reduced compared with CG (basal line). Apoptosis rates of FSH-2 and LH-2 group were the minimum in FSH groups and LH groups. These results were similar to an earlier report (Elmogy \& Takeda, 2009). $10 \mathrm{IU} / \mathrm{mL}$ FSH addition was the optimal concentration for IVM of sheep oocytes.

The significant lower GVBD rate was found in the LH-treated group as compared with the control group (Li et al., 2011). LH inhibited the GVBD of oocytes in its early stage during IVM, because LH could prolong the initiation of GVBD for sheep oocytes. In the current study, the maximum GVBD rate was found in the FSH-2 group. The GVBD rate of the LH-2 group was higher than that of the CG and LH-4 groups. The results demonstrated that the addition of $10 \mathrm{IU} / \mathrm{mL} \mathrm{FSH}$ or $10 \mu \mathrm{g} / \mathrm{mL} \mathrm{LH}$ to the IVM medium could increase the GVBD rate. However, these results were inconsistent with an early report (Li et al., 2009). Therefore, the effects of LH on GVBD rate of sheep oocytes still need to be thoroughly investigated.

For FSH to exert its effects, the receptors must be present in the follicle cells. The cumulus cells had high numbers of FSH receptors (Peng et al., 1991; Xiao et al., 2014). The authors' previous studies demonstrated that FSHR was expressed in the sheep ovaries (Wei et al., 2012; 2014). In the present study, FSHR, LHR and GnRHR mRNAs were also detected in sheep cumulus cells when IVM media were supplemented with $\mathrm{FSH}$, with the greatest increment in the presence of $10 \mathrm{IU} / \mathrm{ml} \mathrm{FSH}$. However, FSH had no obvious influence on the expression of GnRHR mRNA. The outcomes were in agreement with the report of Sullivan et al. (2013).

The FSH was more effective than LH owing to higher FSH receptor levels in COCs of yak oocytes than the levels of the LH receptor. Addition of FSH to the IVM medium had a greater effect on the increase of FSHR and LHR mRNA expression levels than that of LH (Xiao et al., 2014). The findings in this study supported this effect of FSH since the expression levels of FSHR mRNAs and proteins in FSH-treated COCs were higher than that in $\mathrm{LH}$-treated groups.

The FSH and LH concentrations in the IVM medium supplemented with various doses of FSH and LH were detected using ELISA kits. The outcomes verified preliminarily that supplementing FSH to IVM medium could increase FSH levels, but decrease LH and P concentrations in the IVM medium. The effects of FSH and its mechanism still need to be investigated in the future.

\section{Conclusions}

Follicle stimulating hormone and LH supplemented into IVM medium could promote the maturation rate, reduce the apoptosis rate of sheep oocytes, and increase the GVBD rate and FSH concentrations in IVM medium fluid, decrease LH concentrations. Additionally, supplement of 10 and $20 \mathrm{IU} / \mathrm{mL} \mathrm{FSH}$ enhanced expression levels of FSHR, LHR, and GnRHR mRNAs of sheep COCs. The present findings provided a better understanding of the effects and mechanisms of FSH and LH regulation of IVM of oocytes of Lanzhou fat-tailed sheep. They also enabled the authors to overcome many problems related to facilitating fecundity and treating follicular and ovarian diseases of Lanzhou fat-tailed sheep and other animals.

\section{Acknowledgements}

This work was supported by the National Natural Science Foundation of the People's Republic of China (Grant no. 31460684). Manuscript English was checked using Ginger tools online.

\section{Authors' Contributions}

SW designed the experiments and wrote the manuscript. DY measured receptor gene expression. LL conducted western blotting. LH performed apoptosis assays. GZ carried out the statistical analyses. All authors interpreted the data, critically revised the manuscript for important intellectual content, and approved the final version.

\section{Conflict of Interest Declaration}

All authors have declared no conflict of interest. This study has no conflict of interest.

\section{References}

Arias-Álvarez, M., García-García, R.M., López-Tello, J., Rebollar, P.G., Gutiérrez-Adán, A. \& Lorenzo, P.L., 2016. In vivo and in vitro maturation of rabbit oocytes differently affects the gene expression profile, mitochondrial distribution, apoptosis and early embryo development. Reprod. Fertil. Dev. DOI:10.1071/RD15553.

Calder, M.D., Caveney, A.N., Smith, L.C. \& Watson, A.J., 2003. Responsiveness of bovine cumulus- oocyte-complexes $(\mathrm{COC})$ to porcine and recombinant human $\mathrm{FSH}$, and the effect of $\mathrm{COC}$ quality on gonadotropin receptor and $\mathrm{C} \times 43$ marker gene mRNAs during maturation in vitro. Reprod. Biol. Endocrinol. 1,14-16.

de Frutos, C., Vicente-Perez, R. \& Ross, P,J., 2013. Determining the requirements for LH and FSH during sheep in vitro oocyte maturation. Reprod. Fertil. Devel. 26(1), 200-203.

Elmogy, M. \& Takeda, M., 2009. Biochemical and cellular changes during the programmed cell death in the fat body cells of the silkworm bombyx mori. Efflatounia 9, 18-28.

Li, K., Ni, H., Zhao, Y., Liu, Y., Qu, Y., Li, X. \& Guo, Y., 2011. LH plays a role in enhancing the nuclear and cytoplasm synchronization during $i$ maturation of ovine oocytes. Agricul. Sci. China 10(1), 136-141.

Lu, H.N. \& Qi, Y.J., 2013. Research progress on the factors influencing maturation in vitro of sheep oocyte. Heilongjiang 
Agricul. Sci. 9, 147-150.

Metcalfe, A.D., Hunter, H.R., Bloor, D.J., Lieberman, B.A., Picton, H.M. \& Leese, H.J., 2004. Expression of 11 members of the BCL-2 family of apoptosis regulatory molecules during human preimplantation embryo development and fragmentation. Mol. Reprod. Dev. 68, 35-50.

Nandi, S., Ravindranatha, B.M., Gupta, P.S. \& Sarma, P.V., 2002. Timing of sequential changes in cumulus cells and first polar body extrusion during in vitro maturation of buffalo oocytes. Theriogenol. 57,1151--1159.

Nor-Azlina, A.A., Nurul, A.O., Habsah, B., Wan, K.E. \& Noor, H.H., 2014. Influence of Early Apoptosis Incidence on In Vitro Maturation of Bovine Oocytes. 4th International Conference on Agriculture and Animal Science (CAAS 2013). APCBEE Procedia. 8, 272-276.

Peng, X.R. Hsueh, A.J. LaPolt, P.S. Bjersing, L. \& Ny, T., 1991. Localization of luteinizing hormone receptor messenger ribonucleic acid expression in ovarian cell types during follicle development and ovulation. Endocrinology 129, 3200-3207.

Hobbs, R.J,, Howard, J., Wildt, D.E. \& Comizzoli, P., 2012. Absence of seasonal changes in FSHR gene expression in the cat cumulus-oocyte complex in vivo and in vitro. Reprod. 144, 111-122.

Sullivan, R.R., Faris, B.R., Eborn, D., Grieger, D.M., Cino-Ozuna, A.G. \& Rozell, T.G., 2013. Follicular expression of follicle stimulating hormone receptor variants in the ewe. Reprod. Biol. Endocrinol. 11,113.

Tripathi, S.K., Farman, M., Nandi, S., Mondal, S., Gupta, P.S.P. \& Kumar, V.G., 2016. In vitro culture of oocytes and granulosa cells collected from normal, obese, emaciated and metabolically stressed ewes. Anim. Reprod. Sci. 170: 83-89.

Tsafriri, A., Cao, X. \& Ashkenazi, H., 2005. Resumption of oocyte meiosis in mammals: On models, meiosis-activating sterols, steroids and EGF factors. Mol. Cell. Endocrinol. 234, 37-45.

Van Tol, H.T., Van Eijk, M.J., Mummery, C.L., Van den Hurk, R. \& Bevers M.M., 1996, Influence of FSH and hCG on the resumption of meiosis of bovine oocytes surrounded by cumulus cells connected to membrane granulosa. Mol. Reprod. Dev. 45, 218-224.

Wei, S., Gong, Z., Ma, W., \& Wei, M., 2012. Effects of GnRH agonist on reproductive functions of female rabbits. Anim. Sci. Pap. Rep. 30(1), 73-86.

Wei, S., Chen, S., Wei, B., Liu, Z., \& Bai, T., 2016. Estrus synchronization schemes and application efficacies in anestrus Lanzhou fat-tailed ewes. J. Appl. Anim. Res. 44(1), 466-473.

Wei, S., Gong, Z., Dong, J., Ouyang, X., Xie, K. \& Wei, M., 2014. Effects of GnRHa active immunity on FSHR expression and uterine development in prepuberty and non cyclic ewes. Iran. J. Vet. Res. 15(3), 244-249.

Wei, S., Chen, S., Gong, Z., Ouyang, X., An L., Xie, K., Dong, J. \& Wei, M., 2013. Alarelin active immunization influences expression levels of GnRHR, FSHR and LHR proteins in the ovary and enhances follicular development in ewes. Anim. Sci. J. 84, 466-475.

Xiao, X., Zi, X. \& Niu, H., 2014. Effect of addition of FSH, LH and proteasome inhibitor MG132 to in vitro maturation medium on the developmental competence of yak (Bos grunniens) oocytes. Reprod. Biol. Endocrinol. 12, 30-31.

Xu, M., Fazleabas, A.T. \& Shikanov, A., 2011. In vitro oocyte maturation and preantral follicle culture from the lutcalphase baboon ovary produce mature oocytes. Biol. Reprod. 84(4), 689-697.

Yang, M.Y. \& Rajamahendran, R., 2000. Morphological and biochemical identification of apoptosis in small, medium, and large bovine follicles and the effects of follicle-stimulating hormone and insulin-like growth factor-I on spontaneous apoptosis in cultured bovine granulosa cells. Biol. Reprod. 62,1209-1217.

Yang, S., LI, Y. \& Zhang, Y., 2015. In vitro Maturation of Tan Sheep Oocytes. Agricul. Sci. Technol. 16(9), $1865-1868$.

Zhang, C., 2010. Germplasm resources protection and development for Lanzhou fat-tailed sheep. Anim. Husb. J. China. 46(18), 7-10.

Zhao, Z., Li, R., Mo, X., 2013. Effect of FSH on the in vitro developmental competence of sheep oocytes. Heilongjiang Anim. Husb. Vet. Sci. 3, 38-39.

Zou, J. \& Huo, S.D., 2012. Effects of HCG on maturation in vitro of oocytes. China Herbivores 3(6), 71-72. 